\title{
Accumulation of Phenolic Compounds and Glucosinolates in Sprouts of Pale Green and Purple Kohlrabi (Brassica oleracea var. gongylodes) under Light and Dark Conditions
}

\author{
Ramaraj Sathasivam ${ }^{1}{ }^{(D}$, Min Cheol Kim ${ }^{1}$, Hyeon Ji Yeo ${ }^{1}$, Bao Van Nguyen ${ }^{2}$, Soo In Sohn ${ }^{3} \mathbb{D}$, Sang Un Park ${ }^{1,2, *(\mathbb{D})}$ \\ and Joonyup $\operatorname{Kim}^{4, *}$ \\ 1 Department of Crop Science, Chungnam National University, 99 Daehak-ro, Yuseong-gu, \\ Daejeon 34134, Korea; ramarajbiotech@gmail.com (R.S.); mincheol2641@naver.com (M.C.K.); \\ gusw17627@gmail.com (H.J.Y.) \\ 2 Department of Smart Agriculture Systems, Chungnam National University, 99 Daehak-ro, Yuseong-gu, \\ Daejeon 34134, Korea; nguyenvanbao@tuaf.edu.vn \\ 3 Biosafety Division, Department of Agricultural Biotechnology, Jeonju 55365, Korea; sisohn@korea.kr \\ 4 Department of Horticultural Science, Chungnam National University, 99 Daehak-ro, Yuseong-gu, \\ Daejeon 34134, Korea \\ * Correspondence: supark@cnu.ac.kr (S.U.P.); jykim12@cnu.ac.kr (J.K.); Tel.: +82-42-821-5730 (S.U.P.); \\ +82-42-821-5738 (J.K.); Fax: +82-42-822-2631 (S.U.P.); +82-42-823-1382 (J.K.)
}

Citation: Sathasivam, R.; Kim, M.C.; Yeo, H.J.; Nguyen, B.V.; Sohn, S.I.; Park, S.U.; Kim, J. Accumulation of Phenolic Compounds and Glucosinolates in Sprouts of Pale Green and Purple Kohlrabi (Brassica oleracea var. gongylodes) under Light and Dark Conditions. Agronomy 2021, 11, 1939. https://doi.org/10.3390/ agronomy11101939

Academic Editor:

Antonios Chrysargyris

Received: 26 August 2021

Accepted: 24 September 2021

Published: 27 September 2021

Publisher's Note: MDPI stays neutral with regard to jurisdictional claims in published maps and institutional affiliations.

Copyright: (c) 2021 by the authors Licensee MDPI, Basel, Switzerland. This article is an open access article distributed under the terms and conditions of the Creative Commons Attribution (CC BY) license (https:/ / creativecommons.org/licenses/by/ $4.0 /)$

\begin{abstract}
Kohlrabi is considered an important dietary vegetable worldwide. In this study, we investigated the growth and accumulation of phenolic compounds (PCs) and glucosinolates in sprouts of pale green and purple kohlrabi (Brassica oleracea var. gongylodes) in response to light and dark conditions. Pale green kohlrabi presented high fresh weight and root length irrespective of light treatment, whereas under dark conditions, it presented higher fresh weight and shoot length than purple kohlrabi. In contrast, the root length of both kohlrabies increased markedly under light conditions compared to that under dark conditions. Thirteen PCs and eight glucosinolates were detected and quantified in 10-day-old pale green and purple kohlrabies. In both kohlrabies, the individual and total phenolic levels were much higher under the light treatment than under the dark treatment. Under light and dark conditions, the total phenolic content was 6362.13 and $5475.04 \mu \mathrm{g} / \mathrm{g}$ dry weight in the pale green kohlrabi, respectively, whereas in the purple kohlrabi, it was 10,115.76 and $9361.74 \mu \mathrm{g} / \mathrm{g}$ dry weight, respectively. Dark conditions favored higher accumulation of glucosinolates than light conditions. Progoitrin, neoglucobrassicin, glucoerucin, and 4-methoxyglucobrassicin were the predominant glucosinolates in both kohlrabies and were present in much higher amounts in the pale green kohlrabi. In pale green kohlrabi under dark conditions, the total glucosinolates content was 4.75 and 2.62 times higher than that of the purple kohlrabi under light and dark conditions, respectively. Among individual glucosinolates, in the pale green kohlrabi under the dark condition, progoitrin was found to have the highest content, which was 90.28 and 54.51 times higher than that in the purple kohlrabi under light and dark conditions, respectively. These results show that the phenolic and glucosinolates levels varied widely, and these variations between the two types of kohlrabi under both light and dark conditions were significant. Our findings suggest that light and dark conditions enhance the accumulation of PCs and glucosinolates, respectively, during the development of kohlrabi seedlings.
\end{abstract}

Keywords: Brassica oleracea; kohlrabi; phenolic compounds; glucosinolates; light and dark

\section{Introduction}

Brassica oleracea var. gongylodes, commonly known as kohlrabi, is a biennial vegetable belonging to the family Cruciferae (Brassicaceae). Kohlrabi is a cool weather plant and has a long leafy stem and round bulb. The most common cultivars are pale green kohlrabi (PGK) and purple kohlrabi (PK) [1]. The taste and texture of kohlrabi are similar to 
those of broccoli stems and cabbage, although it is slightly sweeter. The swollen bulblike stem is widely used in salads and soups but can also be roasted or sautéed. Its leaves and stems are slightly crunchy and cook similarly to collard greens [2]. Similar to other members of the Brassicaceae, kohlrabi contains health-promoting secondary metabolites such as glucosinolates, anthocyanins, carotenoids, and phenylpropanoids. Kohlrabi, especially, contains good amounts of many carbohydrates, amino acids, organic acids, vitamins, and minerals [3]. Plant metabolism can be subdivided into primary and secondary metabolism. Primary and secondary metabolites are the end products and intermediates of these metabolisms [4]. Primary metabolites are directly responsible for the physiological processes including normal growth, development, and reproduction in living organisms, and secondary metabolites are involved in plant defense and are used as medicines for human health. Three main classes of secondary metabolites are produced by plants: terpenoid, phenolic, and nitrogen/sulfur-containing compounds [5,6].

Phenolic compounds (PCs) are plant secondary metabolites that are mostly produced through the shikimate/phenylpropanoid pathways. They are found rarely in bacteria, fungi, and algae. Their basic structure is that of a phenyl group (six carbons) and propene tail (three carbons) [7,8]. Various types of PCs play an important role in plants. For example, they are responsible for red and orange color pigmentation which helps to attract pollinators, and they protect plants from UV irradiation, insects, and fungi [9]. In addition, the efficacy of PCs in humans is attracting attention. Epidemiological studies suggest that PCs prevent cancer and cardiovascular diseases. Moreover, PCs have antioxidant properties, such as removing free radicals, making them effective in antiaging agents [10].

Glucosinolates are natural plant products that have a spicy taste. In 1831, sinalbin, a type of glucosinolate, was first identified in white mustard. They have three basic structures: a $\beta$-thioglucose, a sulfonated oxime group, and a variable side chain originated from an amino acid [11]. More than 200 types of glucosinolates are known to occur in nature. Predominantly, Brassicales plants such as Brassicaceae, Caricaceae, and Capparidaceae contain glucosinolates $[12,13]$. They can be classified as aliphatic, indolyl, or aromatic glucosinolates, depending on the type of derived amino acids [13]. Glucosinolates are hydrolyzed to isothiocyanates, nitriles, thiocyanates, epithionitriles, and oxazolidinethiones by the enzyme myrosinase. These products act as bioactive compounds in plants and animals. In the case of humans, they have antioxidant activity as well as anticancer effects in bladder, colon, and lung cancers. In addition, plants use these as self-defense materials for protection from animals, insects, and fungi $[1,14,15]$.

Light is not only important to plants for photosynthesis but also acts as a potent regulator in growth, development, physiology, and metabolism [16]. Light is the primary energy source for life on Earth and comes in a wide range of wavelengths, from UV to farred, and is absorbed through different types of photoreceptors. Plants show physiological and morphological differences according to the presence or absence of light [17].

In this study, we aimed to investigate the effect of light on the accumulation of secondary metabolites in kohlrabi sprouts. We exposed both PGK and PK sprouts to light and dark conditions for 10 days. Subsequently, we investigated the growth (fresh weight, shoot, and root length) and analyzed the secondary metabolites (glucosinolates, and PCs) using high-performance liquid chromatography (HPLC). This study will help to understand the relationship between the light factor and the content of secondary metabolites present in kohlrabi sprouts.

\section{Materials and Methods}

\subsection{Plant Materials}

The seeds of pale green kohlrabi (cultivar Green kohl) and purple kohlrabi (cultivar Ruby cap), Brassica oleracea var. gongylodes (Gongylodes group), belonging to the family Cruciferae (Brassicaceae), were purchased from Asia Seeds Ltd. (Seoul, Korea). Before sowing in soil, the seeds were soaked in water for $24 \mathrm{~h}$ and incubated at $25^{\circ} \mathrm{C}$ in a growth chamber under white fluorescent lights $\left(35 \mu \mathrm{mol} \mathrm{s}^{-1} \mathrm{~m}^{-2}\right)$. The experiment was performed 
under two conditions: dark condition (continuously grown under dark (24 h)) and light condition (under 16/8 h light/dark). The germinated sprouts were harvested 10 days after sowing and their fresh weight, shoot length, and root length were measured. Then, the samples were frozen immediately in liquid nitrogen for further analysis.

\subsection{Extraction of Glucosinolates and HPLC Analysis}

Glucosinolates were extracted and analyzed as described by Yeo et al. [18], with slight modifications. Freeze-dried PGK and PK samples $(100 \mathrm{mg})$ were mixed with $4.5 \mathrm{~mL}$ of $70 \%(v / v)$ methanol and incubated at $70{ }^{\circ} \mathrm{C}$ for $5 \mathrm{~min}$ and mixed thoroughly by vortexing. Then, the mixture was centrifuged at $4{ }^{\circ} \mathrm{C}$ for $10 \mathrm{~min}$ at $14,000 \mathrm{rpm}$. The supernatant was filtered through a diethylaminoethanol Sephadex A-25 column (GE Healthcare, Uppsala, Sweden) and washed with $3 \mathrm{~mL}$ of sterile distilled water. For desulfation, $75 \mu \mathrm{L}$ of purified arylsulfatase was added to this eluted mixture and incubated at room temperature overnight. The next day, the mixture was eluted into a clean $2.0 \mathrm{~mL}$ Eppendorf tube with $0.5 \mathrm{~mL}$ of ultrapure water and passed through a $0.22 \mu \mathrm{m}$ PTFE syringe filter (Sterlitech Corp., Kent, WA, USA) into amber screw thread vials (Thermo Fisher Scientific, Waltham, MA, USA). The protocol for measurement of glucosinolate content ( $\mu \mathrm{g} / \mathrm{g}$ dry weight (DW)) by HPLC was similar to that described by Yeo et al. [18]. Each compound was identified based on their peak area ratios, and quantification of each compound was based on the peak areas, retention time, and response factor relative to that of the external standard desulfosinigrin (Sigma-Aldrich Co., Ltd., St. Louis, MO, USA).

\subsection{Extraction of PCs and HPLC Analysis}

PCs were analyzed by the protocol described by Yeo et al. [18]. A solution of $3 \mathrm{~mL}$ of $80 \% \mathrm{MeOH}$ was added to $100 \mathrm{mg}$ of powdered sample, vortexed for $1 \mathrm{~min}$, and sonicated for $1 \mathrm{~h}$ at $37^{\circ} \mathrm{C}$. Then, the mixture was centrifuged at $4{ }^{\circ} \mathrm{C}$ for $15 \mathrm{~min}$ at $10,000 \mathrm{rpm}$. The above clear supernatants were collected and filtered into amber screw thread vials (Thermo Fisher Scientific, Waltham, MA, USA) with a $0.45 \mu \mathrm{m}$ PTFE syringe filter (Millipore, Bedford, MA, USA). The HPLC conditions and gradient program were similar to those of the protocol described by Yeo et al. [18]. Each PC was identified based on the retention time, peak areas, and spiking test results. The phenolic content ( $\mu \mathrm{g} / \mathrm{g} \mathrm{DW})$ of samples was quantified with reference to a corresponding calibration curve.

\subsection{Statistical Analysis}

Data were statistically analyzed using the Statistical Analysis System Version 9.4 (SAS Institute, Inc., Cary, NC, USA). The significant difference among means was evaluated using Duncan's multiple range test. All data were calculated as mean \pm standard deviation of triplicate experiments. Principal component analysis (PCA) of the 21 metabolites identified in the PGK and PK sprouts grown under light and dark conditions was performed using MetaboAnalyst 5.0 with autoscaling.

\section{Results and Discussion}

\subsection{Effect of Light and Dark Treatment on the Growth of PGK and PK Sprouts}

The fresh weight, shoot length and root length of 10-day-old PGK and PK sprouts in response to light and dark conditions were measured (Figure 1). With different light treatments, both cultivars showed variations in all the studied growth parameters. 


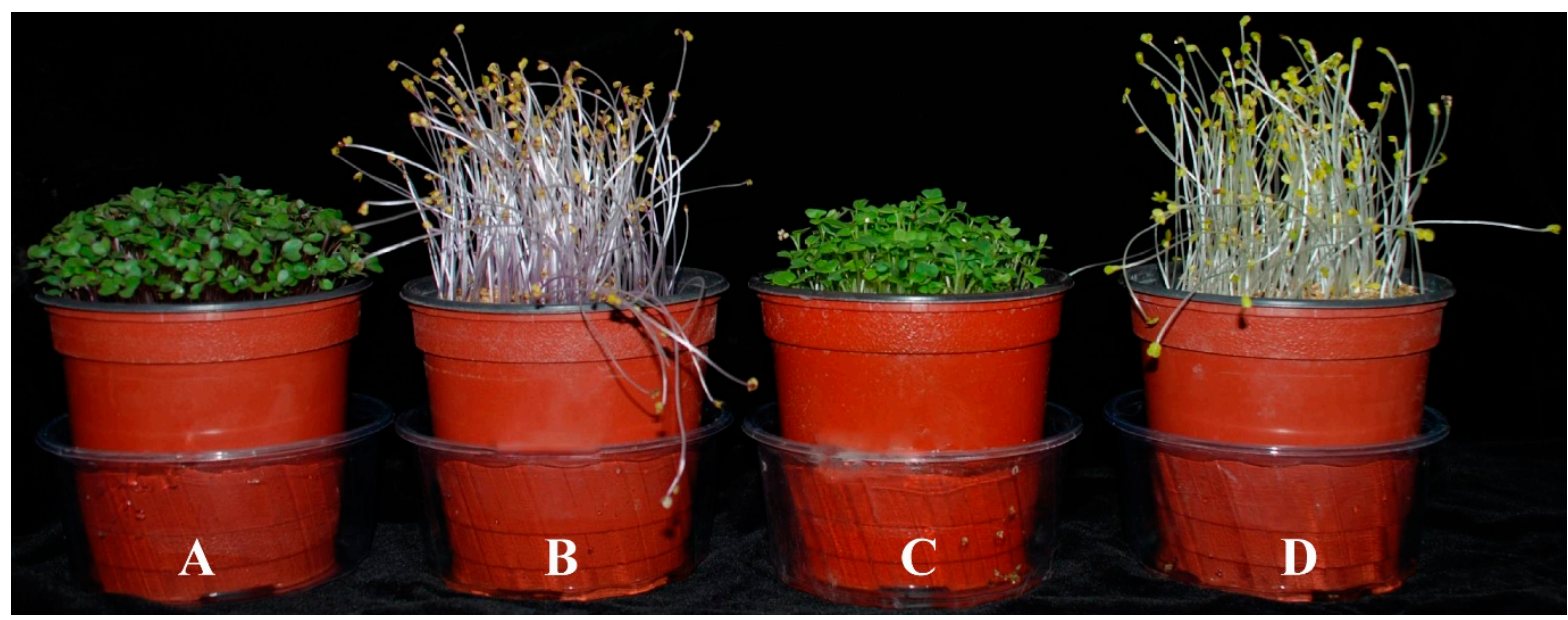

Figure 1. Kohlrabi sprout grown under light and dark conditions for 10 days. (A) Purple kohlrabi grown under light, (B) purple kohlrabi grown under dark, (C) pale green kohlrabi grown under light, and (D) pale green kohlrabi grown under dark.

PGK produced a high fresh weight and root length irrespective of the light treatment. It was observed that dark conditions had a higher influence on PK than on PGK. Under dark conditions, the fresh weight increased by 7.0 and $2.0 \mathrm{mg}$ in PK and PGK, respectively, compared to that under light conditions (Figure 2). A similar trend was observed for the shoot length in both PGK and PK for the studied treatments. It was observed that dark conditions had a much higher influence than light conditions on the shoot length of both kohlrabies. Under dark conditions, the shoot length was 4.6 and $3.96 \mathrm{~cm}$ more in PGK and PK, respectively, than in sprouts under light conditions. In contrast, the roots of PGK and PK grown under light conditions were $3.56 \mathrm{~cm}$ and $1.34 \mathrm{~cm}$ longer, respectively, than of sprouts grown under dark conditions.
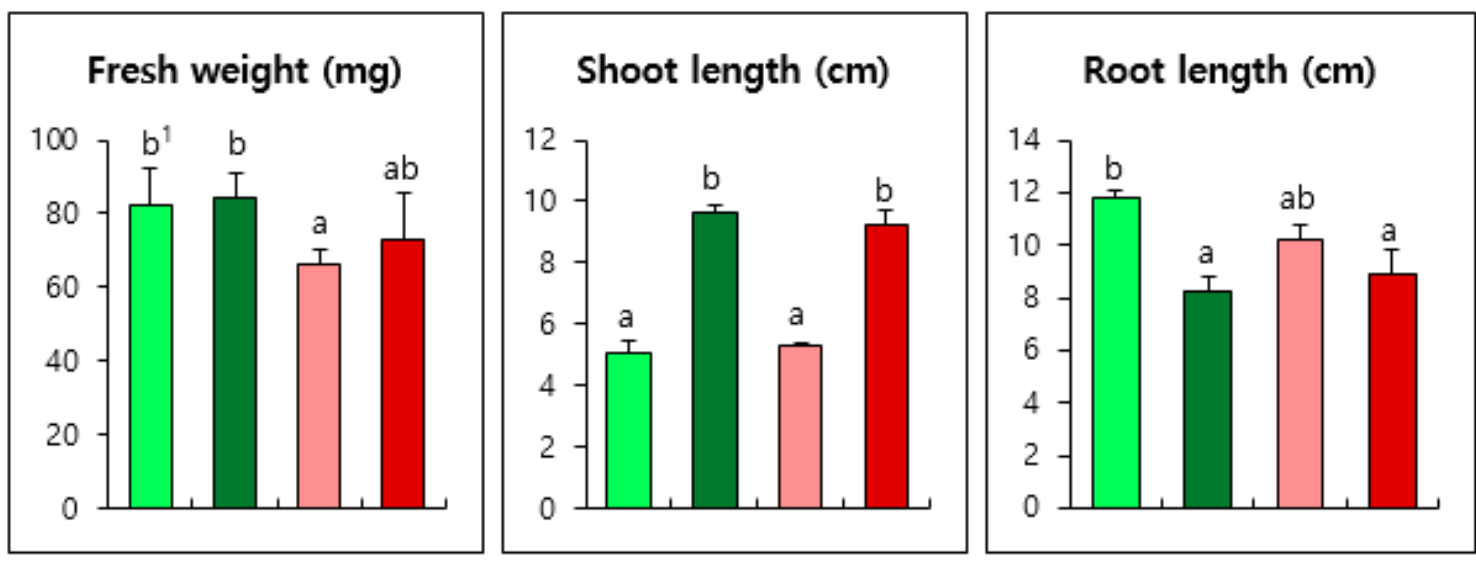

\section{Pale Green Kohlrabi Light $\square$ Pale Green Kohlrabi Dark \\ Purple Kohlrabi Light $\quad \square$ Purple Kohlrabi Dark}

Figure 2. Effect of light and dark treatment on the growth of pale green and purple kohlrabi sprouts. ${ }^{1}$ Values followed by different letters within a column indicate a significant difference $(p<0.05)$ between areas for that parameter using DMRT $(n \geq 5$, mean $\pm \mathrm{SD})$.

In this study, the PGK exhibited a higher fresh weight and root length than PK, irrespective of the light treatment. It was noted that dark conditions showed a higher influence on PK than on PGK wherein shoot length and fresh weight were higher in both cultivars under dark conditions. The root length of both kohlrabies responded positively to light conditions. The growth trend observed in this study was similar to that observed 
previously for radish and buckwheat seedlings. The shoot length and seedling weight of radish [19] and of buckwheat sprout [20] were high under dark conditions. In another study, Kim et al. [21] reported that the maximum biomass was achieved for common buckwheat sprouts cultured under darkness for approximately 8 days.

\subsection{Accumulation of PCs during the Development of PGK and PK Sprouts under Dark and Light Conditions}

The analysis of 10-day-old PGK and PK sprouts revealed the presence of 13 PCs, i.e., gallic acid, 4-hydroxybenzoic acid, catechin hydrate, chlorogenic acid, caffeic acid, epicatechin, $p$-coumaric acid, ferulic acid, benzoic acid, rutin, trans-cinnamic acid, quercetin, and kaempferol (Table 1). Both kohlrabies exposed to light treatment showed higher total phenolic content than under dark treatment. Specifically, the PK showed the highest accumulation of individual and total PCs when compared to PGK. The total PCs levels were $4640.72,3753.63$, and $754.02 \mu \mathrm{g} / \mathrm{g}$ higher in the PK under light (PKL) condition than in PGK under dark (PGKD), PGK under light (PGKL), and PK under dark (PKD) conditions, respectively. Among the identified compounds, the levels of catechin hydrate, caffeic acid, epicatechin, $p$-coumaric acid, rutin, trans-cinnamic acid, kaempferol, and total PCs were enhanced owing to light conditions. The accumulation of gallic acid, chlorogenic acid, and benzoic acid was enhanced under dark conditions, whereas 4-hydroxybenzoic acid, ferulic acid, and quercetin showed a mixed result under both light and dark conditions. Among the compounds, the accumulation of rutin, benzoic acid, and epicatechin was much more than that of the other compounds. The accumulation of rutin was much higher than that of the other individual PCs irrespective of light and dark conditions. The rutin content ranged from 1002.35 to $6852.39 \mu \mathrm{g} / \mathrm{g}$ DW (Table 1). A higher level of rutin content was found in PKL sprouts, by 6.84, 3.16, and 1.2 times, than in the PGKD, PGKL, and PKD sprouts, respectively. Following rutin, the second most prevalent compound was benzoic acid. The scenario of benzoic acid levels was different than that for rutin. Although rutin content was very high in PK, benzoic acid content was extremely high in PGK irrespective of light and dark conditions. The benzoic acid content in both kohlrabies under light and dark conditions ranged from 523.71 to $2083.99 \mu \mathrm{g} / \mathrm{g}$ DW (Table 1). A higher level of benzoic acid content, by 3.98, 1.71, and 1.12 times, was found in PGKD sprouts than in the PKL, PKD, and PGKL sprouts, respectively. The third most prevalent compound was epicatechin. The epicatechin content in both kohlrabies under light and dark conditions ranged from 800.69 to $1350.25 \mu \mathrm{g} / \mathrm{g}$ DW. In the PKL sprouts, a higher level of epicatechin content, by 1.69, 1.45, and 1.22 times, was found than that in the PGKD, PGKL, and PKD sprouts, respectively. The levels of ferulic acid in both kohlrabies under light and dark conditions ranged from 800.69 to $1350.25 \mu \mathrm{g} / \mathrm{g}$ DW (Table 1). The PGKD sprouts exhibited a higher level of ferulic acid content, by 7.76, 5.93, and 2.19 times, than the PKD, PKL, and PGKL sprouts, respectively. In both kohlrabies under light and dark conditions, the accumulation trend of PCs from the highest to the lowest amounts was catechin hydrate, 4-hydroxybenzoic acid, quercetin, kaempferol, $p$-coumaric acid, gallic acid, chlorogenic acid, trans-cinnamic acid, and caffeic acid, and their highest values were 262.03, 238.98, $232.77,201.49,170.44,176.31,92.63,78.38$, and $40.79 \mu \mathrm{g} / \mathrm{g}$ DW, respectively. These results indicate that light enhanced most of the individual PCs and total phenolic content in both PGK and PK.

The importance of light, the different wavelengths of which are absorbed through specific photoreceptors, in the growth, physiology, and metabolic processes of plants is well recognized. It has been demonstrated that phytochrome mechanisms, light duration, quality, and intensity are the prime factors that affect the accumulation of PCs [22]. In addition, light triggers the photoreceptors that then translocate to the nucleus, leading to the enhanced transcription of carotenoid biosynthetic pathway genes [23,24]. When compared to Tartary buckwheat sprouts grown under dark conditions, sprouts under light showed increased gene expression in the carotenoid biosynthetic pathway in the T10 cultivar and increased carotenoid accumulation in both the T8 and T10 cultivars. The major carotenoids found in Tartary buckwheat were $\beta$-carotene and lutein, and these carotenoids 
were significantly higher in the sprouts grown under light conditions [25]. An earlier study reported that the content of secondary metabolite differed among the light treatments. The levels of anthocyanin, flavonols, and phenolic acids were enhanced quickly by irradiation, whereas those of dihydrochalcones, flavanols, and procyanidins were not altered in both mature or ripe apple fruits [26]. Our results are in agreement with those of previous studies that reported enhanced PCs accumulation with light treatment in different plant species such as Arabidopsis seedlings [27], peach shoots [28], soybean seedlings [29], and tulip bulbs [30]. The accumulation of PCs may vary because of cultivars, and among parts within the individual plant, as observed in several crops such as turnip greens and turnip tops [31], pak choi [32], and tronchuda cabbage [33,34]. In another study, it was noted that the levels of PCs were higher in PK than in PGK [1]. Cyanidin is the only reported aglycone present in Tartary buckwheat sprouts, whereas the major anthocyanin is cyanidin $3-O$-rutinoside $[35,36]$, which is likely the main contributor to the red color of Tartary buckwheat sprouts. These results are inconsistent with those of our study, where we found much variation in both PGK and PK. Based on these results, it is suggested that the light treatment increased the production of PCs during kohlrabi seedling development.

Table 1. Accumulation of phenolic compounds ( $\mu \mathrm{g} / \mathrm{g} \mathrm{DW})$ during the sprout development of pale green and purple kohlrabi under dark and light conditions.

\begin{tabular}{|c|c|c|c|c|}
\hline \multirow{2}{*}{ Trivial Name } & \multicolumn{2}{|c|}{ Pale Green Kohlrabi } & \multicolumn{2}{|c|}{ Purple Kohlrabi } \\
\hline & Light & Dark & Light & Dark \\
\hline Gallic acid & $100.60 \pm 3.73 c^{1}$ & $168.70 \pm 4.71 \mathrm{a}$ & $121.00 \pm 6.78 \mathrm{~b}$ & $176.31 \pm 10.84 \mathrm{a}$ \\
\hline 4-hydroxybenzoic acid & $110.43 \pm 6.51 b$ & $106.76 \pm 12.06 \mathrm{c}$ & $183.39 \pm 8.32 b$ & $238.98 \pm 8.28 \mathrm{a}$ \\
\hline Catechin hydrate & $262.03 \pm 4.28 \mathrm{a}$ & $205.25 \pm 14.13 \mathrm{~b}$ & $243.94 \pm 49.11 \mathrm{ab}$ & $143.31 \pm 19.16 \mathrm{c}$ \\
\hline Chlorogenic acid & $80.14 \pm 20.62 \mathrm{a}$ & $92.63 \pm 24.15 \mathrm{a}$ & $80.01 \pm 13.19 \mathrm{a}$ & $83.07 \pm 19.40 \mathrm{a}$ \\
\hline Caffeic acid & $38.86 \pm 7.01 \mathrm{a}$ & $19.48 \pm 1.43 \mathrm{~b}$ & $40.79 \pm 6.95 \mathrm{a}$ & $24.88 \pm 1.35 b$ \\
\hline Epicatechin & $930.39 \pm 43.55 c$ & $800.69 \pm 16.91 \mathrm{~d}$ & $1350.25 \pm 76.97 \mathrm{a}$ & $1107.11 \pm 44.57 \mathrm{~b}$ \\
\hline$p$-coumaric acid & $131.97 \pm 2.92 b$ & $93.55 \pm 5.30 c$ & $187.13 \pm 19.45 \mathrm{a}$ & $170.44 \pm 7.36 \mathrm{a}$ \\
\hline Ferulic acid & $272.17 \pm 52.26 \mathrm{~b}$ & $595.38 \pm 32.53 \mathrm{a}$ & $100.46 \pm 19.42 c$ & $76.72 \pm 8.32 c$ \\
\hline Benzoic acid & $1856.83 \pm 102.68 b$ & $2083.99 \pm 133.45 \mathrm{a}$ & $523.71 \pm 23.32 \mathrm{~d}$ & $1221.26 \pm 47.93 c$ \\
\hline Rutin & $2166.00 \pm 177.71 \mathrm{c}$ & $1002.35 \pm 39.62 \mathrm{~d}$ & $6852.39 \pm 75.22 \mathrm{a}$ & $5717.95 \pm 101.61 \mathrm{~b}$ \\
\hline Trans-cinnamic acid & $65.65 \pm 9.14 b$ & $23.41 \pm 2.48 c$ & $78.38 \pm 4.11 \mathrm{a}$ & $29.35 \pm 6.28 c$ \\
\hline Quercetin & $197.01 \pm 10.90 \mathrm{a}$ & $148.95 \pm 31.60 \mathrm{~b}$ & $152.83 \pm 10.96 \mathrm{~b}$ & $232.77 \pm 28.56 \mathrm{a}$ \\
\hline Kaempferol & $150.03 \pm 31.56 \mathrm{ab}$ & $133.91 \pm 34.00 \mathrm{~b}$ & $201.49 \pm 21.03 \mathrm{a}$ & $139.61 \pm 20.27 b$ \\
\hline Total & $6362.13 \pm 171.73 c$ & $5475.04 \pm 272.56 \mathrm{~d}$ & $10,115.76 \pm 168.17 \mathrm{a}$ & $9361.74 \pm 238.39 b$ \\
\hline
\end{tabular}

${ }^{1}$ Values followed by different letters within a column indicate a significant difference $(p<0.05)$ between areas for that parameter using Duncan's multiple range test $(n \geq 3$, mean $\pm \mathrm{SD})$.

3.3. Accumulation of Glucosinolates during the Development of PGK and PK Sprouts under Dark and Light Conditions

Eight glucosinolates, i.e., progoitrin, glucoraphanin, gluconapin, 4-hydroxyglucobrassicin, glucoerucin, glucobrassicin, 4-methoxyglucobrassicin, and neoglucobrassicin were quantified from both PK and PGK under the light and dark treatments (Table 2). Progoitrin, neoglucobrassicin, glucoerucin, and 4-methoxyglucobrassicin were the predominant glucosinolates in both kohlrabies and were especially in high amounts in PGK. The total glucosinolate content in both kohlrabies under light and dark conditions ranged from 5699.33 to $27,048.00 \mu \mathrm{g} / \mathrm{g}$ DW. The PGKD sprouts showed a higher level of total glucosinolates content, by 4.75 and 2.62 times, than the PKL and PKD sprouts, respectively. The level of progoitrin content was much more in the PGKD sprouts than in the PKL and PKD sprouts. A higher progoitrin content, by 90.28 and 54.51 times, was found in PGKD sprouts than in the PKL and PKD sprouts, respectively. The content of neoglucobrassicin was also much higher in the PGKD sprouts than in PKD sprouts. In the PGKD sprouts, a higher level of neoglucobrassicin content, by 5.75 and 2.93 times, was found than in the PKL and PKD sprouts, respectively. The level of glucoerucin was much higher in both PGKD and PKD sprouts than under light conditions. The glucoerucin content in both kohlrabies under 
both treatments ranged from 1327.73 to $3789.29 \mu \mathrm{g} / \mathrm{g}$ DW. In the PGKD sprouts, a higher glucoerucin content, by 2.85 and 2.36 times, was found than in the PKL and PGKL sprouts, respectively. The level of 4-methoxyglucobrassicin was much higher in the PGKD sprouts than in the PGKL sprout. A higher level of 4-methoxyglucobrassicin, by 3.03 times, was found in PGKD sprouts than in the PKL sprouts. The remaining four glucosinolates, i.e., glucoraphanin, gluconapin, glucobrassicin, and 4-hydroxyglucobrassicin, were accumulated at lower amounts. However, in these cases, the dark conditions also favored high accumulation.

It has been reported previously that variation in secondary metabolites in the same species with different colors is a common phenomenon. Similarly, the enhanced accumulation of secondary metabolites owing to light has also been reported. In this study, we analyzed the glucosinolates content in the PGK and PK seedlings after exposure to light and dark conditions and found that glucosinolates content varied between the two cultivars. The number of glucosinolates was shown to vary in the same, but different colored, kale species, wherein HPLC-UV analysis detected 14 glucosinolates in seedlings of red kale, whereas 11 different glucosinolates were found in seedlings of green kale; the total glucosinolates content was 1.42-fold higher in red kale than in green kale [37]. In this study, in both light and dark conditions, the glucosinolates content was the highest in the PGK in comparison to that in the PK. This result was consistent with our previous results, wherein the glucosinolates levels in PGK and PK varied significantly between the two cultivars [1]. In mizuna, compared to the red cultivar, the green cultivar showed the highest accumulation of glucosinolates content [38]. Similarly, a comparison of PCs between green and purple kenaf showed that the leaves of green kenaf had the highest phenolic content; however, the carotenoid content was the highest in the purple cultivar [39]. From these results, it can be observed that the accumulation of secondary metabolites between the two different colored cultivars is significantly different and depended on the kohlrabi cultivars.

Table 2. Accumulation of glucosinolates $(\mu \mathrm{g} / \mathrm{g} \mathrm{DW})$ during the sprout development of pale green and purple kohlrabi under dark and light conditions.

\begin{tabular}{ccccc}
\hline \multirow{2}{*}{ Trivial Name } & \multicolumn{2}{c}{ Pale Green Kohlrabi } & \multicolumn{2}{c}{ Purple Kohlrabi } \\
\cline { 2 - 5 } & Light & Dark & Light & Dark \\
\hline Progoitrin & $5194.60 \pm 804.86 \mathrm{~b}^{1}$ & $11,249.77 \pm 829.59 \mathrm{a}$ & $124.61 \pm 13.49 \mathrm{c}$ & $206.38 \pm 6.74 \mathrm{c}$ \\
Glucoraphanin & $385.00 \pm 50.52 \mathrm{c}$ & $748.13 \pm 37.89 \mathrm{~b}$ & $700.00 \pm 68.20 \mathrm{~b}$ & $1500.63 \pm 146.50 \mathrm{a}$ \\
Gluconapin & $350.06 \pm 55.90 \mathrm{~b}$ & $863.97 \pm 70.95 \mathrm{a}$ & $26.07 \pm 0.00 \mathrm{c}$ & $55.86 \pm 6.45 \mathrm{c}$ \\
4-hydroxyglucobrassicin & $339.09 \pm 45.59 \mathrm{c}$ & $501.66 \pm 45.59 \mathrm{bc}$ & $664.24 \pm 96.54 \mathrm{ab}$ & $803.59 \pm 42.91 \mathrm{a}$ \\
Glucoerucin & $1605.92 \pm 245.79 \mathrm{~b}$ & $3789.29 \pm 350.43 \mathrm{a}$ & $1327.73 \pm 114.38 \mathrm{~b}$ & $3300.35 \pm 94.91 \mathrm{a}$ \\
Glucobrassicin & $832.28 \pm 131.75 \mathrm{a}$ & $899.39 \pm 23.25 \mathrm{a}$ & $689.09 \pm 15.50 \mathrm{ab}$ & $550.38 \pm 59.42 \mathrm{~b}$ \\
4-methoxyglucobrassicin & $2330.30 \pm 356.38 \mathrm{~b}$ & $3851.93 \pm 279.02 \mathrm{a}$ & $1272.81 \pm 24.86 \mathrm{c}$ & $2153.25 \pm 201.67 \mathrm{~b}$ \\
Neoglucobrassicin & $2373.36 \pm 375.72 \mathrm{~b}$ & $5143.88 \pm 378.48 \mathrm{a}$ & $894.80 \pm 46.96 \mathrm{c}$ & $1756.10 \pm 196.15 \mathrm{bc}$ \\
Total & $13,410.58 \pm 2066.50 \mathrm{~b}$ & $27,048.00 \pm 2015.20 \mathrm{a}$ & $5699.33 \pm 379.94 \mathrm{c}$ & $10,326.52 \pm 754.75 \mathrm{bc}$ \\
\hline
\end{tabular}

${ }^{1}$ Values followed by different letters within a column indicate a significant difference $(p<0.05)$ between areas for that parameter using Duncan's multiple range test $(n \geq 3$, mean $\pm \mathrm{SD})$.

\subsection{Profiles of PCs and Glucosinolates during the Development of PGK and PK Sprouts under} Light and Dark Conditions

In total, during sprout development, 21 metabolites were identified in both PGK and PK cultivars grown under dark and light conditions (Figure 3). Among these, the amounts of PCs such as rutin and epicatechin were significantly higher in both cultivars grown under light conditions, whereas benzoic acid was the highest under dark conditions. However, considering glucosinolate content, progoitrin, 4-methoxyglucobrassicin, and neoglucobrassicin were significantly higher in the PGK cultivar than in the PK cultivar grown under light and dark conditions. Overall, the results showed that in both cultivars, light enhanced the accumulation of PCs, whereas the highest accumulation of glucosinolate compounds was found under the dark condition. 

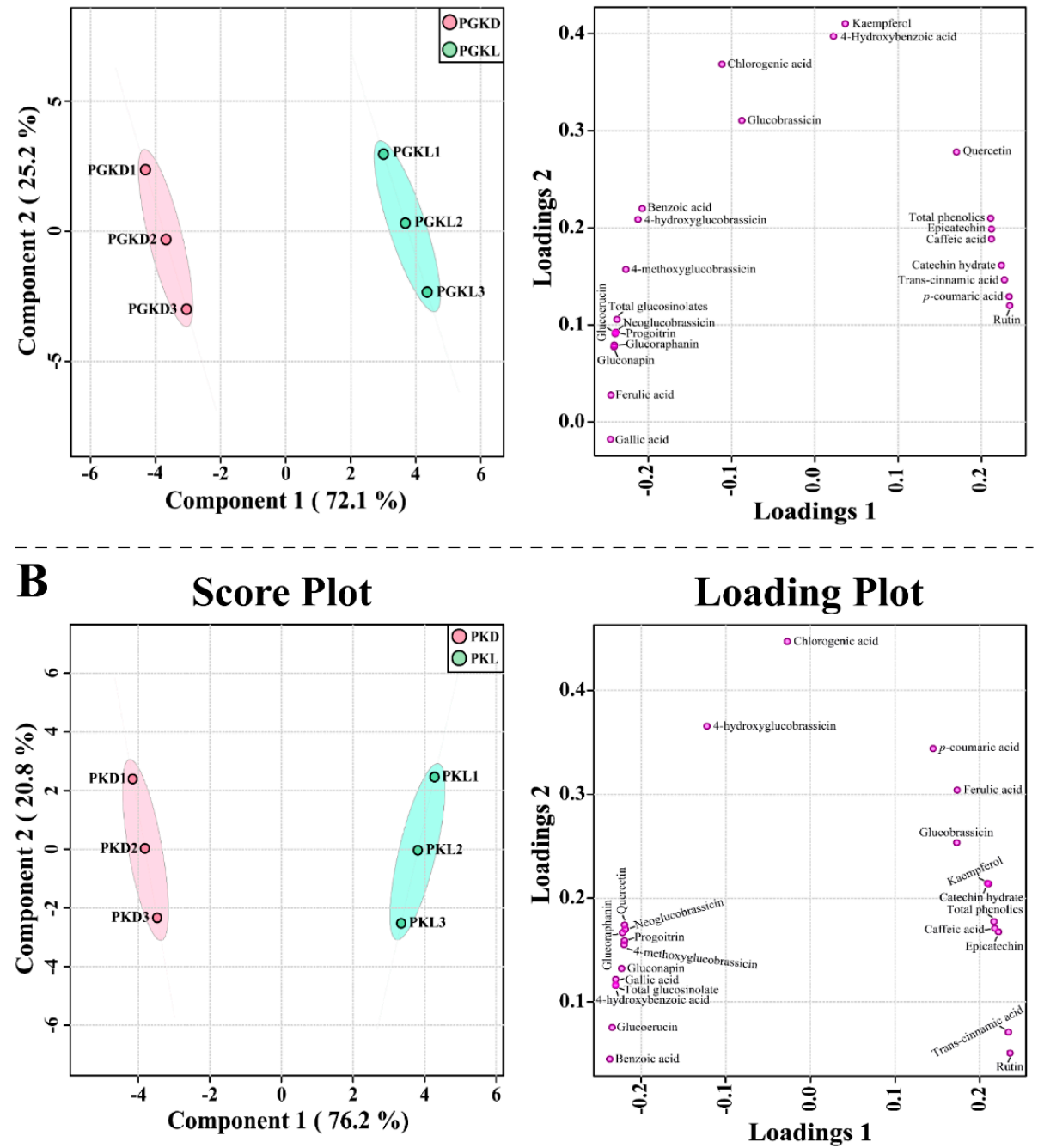

Figure 3. Score plots and loading plots of the principal component analysis (PCA) results acquired from 21 secondary metabolites from (A) PGK and (B) PK sprout grown under light and dark conditions.

The above result supports that obtained through PCA in the two cultivars grown under light and dark conditions. The PCA showed that these metabolites differed between the PGK and PK grown under light and dark conditions along the two main components ( $72.1 \%$ and $25.2 \%$, and $76.4 \%$ and $20.6 \%$ variance, respectively) (Figure 3). In the PGK cultivar grown under light and dark conditions, the most important metabolites of PC1 were gallic acid, ferulic acid, glucoraphanin, gluconapin, and progoitrin, and the associated eigenvector values were $-0.24533,-0.24479,-0.24105,-0.24084$, and -0.2396 , respectively, and the eigenvector values of rutin, $p$-coumaric acid, trans-cinnamic acid, catechin hydrate, and epicatechin were $0.23381,0.23315,0.22753,0.22402$, and 0.21191 , respectively (Figure 3). In the PK cultivar grown under light and dark conditions, the most important metabolites of PC1 were benzoic acid, glucoerucin, 4-hydroxybenzoic acid, gallic acid, and gluconapin, and their eigenvector values were $-0.2375,-0.2348,-0.23079,-0.23066$, and -0.22352 , respectively, and the eigenvector values of rutin, trans-cinnamic acid, epicatechin, caffeic acid, and kaempferol were $0.2359,0.23396,0.22191,0.21747$, and 0.21 , respectively. This showed that the clear separation in the PCA result might be owing to changes in the levels of PCs and glucosinolates.

To identify the most important metabolites between the PGK and PK cultivars grown under light and dark conditions, we performed the partial least squares discriminant 
analysis (PLS-DA). Using the PLS-DA result, the most important metabolites were identified based on the VIP value of the five-component model (Figure 4). In PGK and PK cultivar grown under light and dark conditions, compounds 16 and 17 were identified as discriminating metabolites (VIP $>1$ ), respectively.
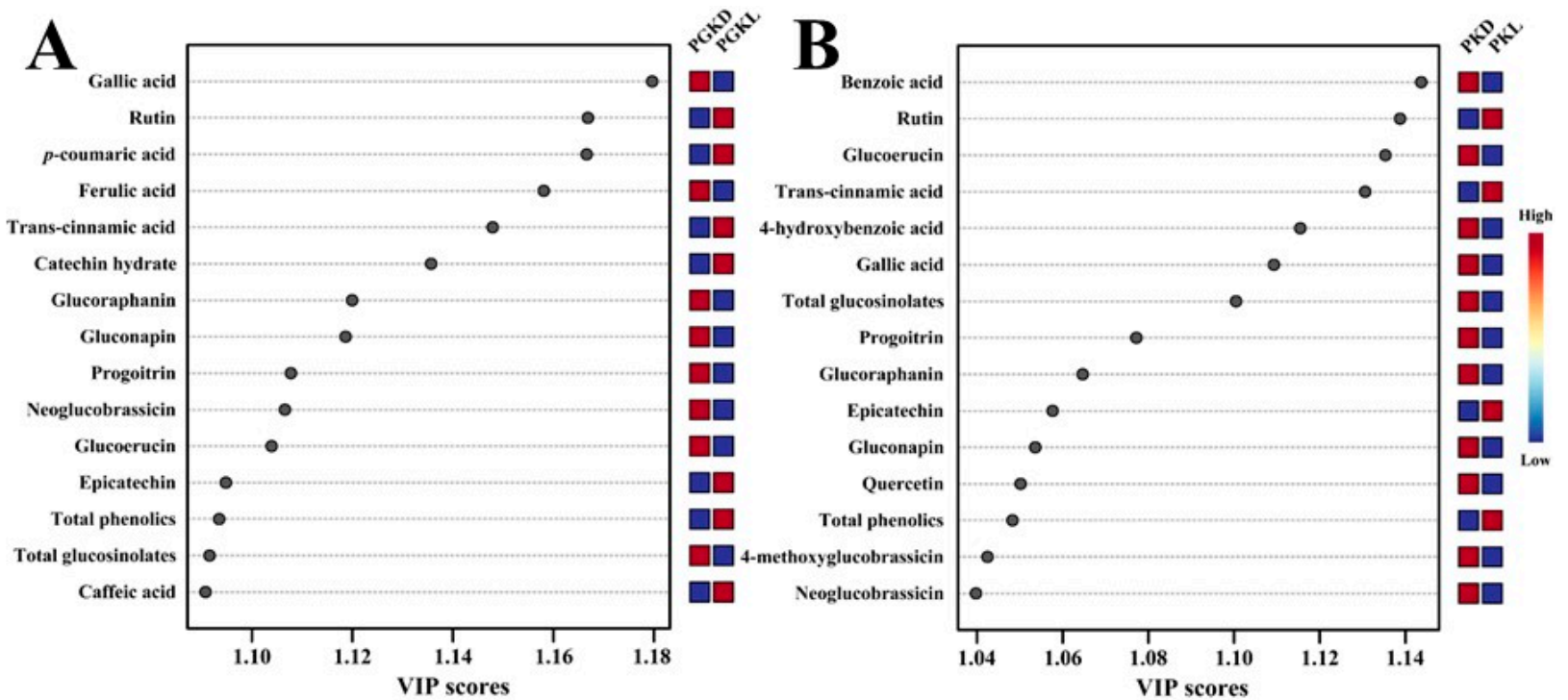

Figure 4. The key compounds separating the PGK (A) and PK (B) cultivars grown under light and dark conditions based on the variable importance in projection (VIP) in partial least squares discriminant analysis (PLS-DA).

The pathway libraries analysis was performed using Arabidopsis thaliana as the source. Eight pathways were identified in both cultivars grown in light and dark conditions (Table S1). Among these, seven pathways were found to be affected (Figure 5) when the PGK and PK were grown under light and dark conditions. Among these pathways, in both cultivars, 4, 3, and 2 pathways were related to flavonoid biosynthesis, phenylpropanoid biosynthesis, and flavone and flavonol biosynthesis, respectively. These results show that the metabolites and their affected pathways have nutraceutical relevance. In Cannabis seeds, the amino acid, carbohydrate, and fatty acid metabolisms were observed to be affected in two different cultivars [40].
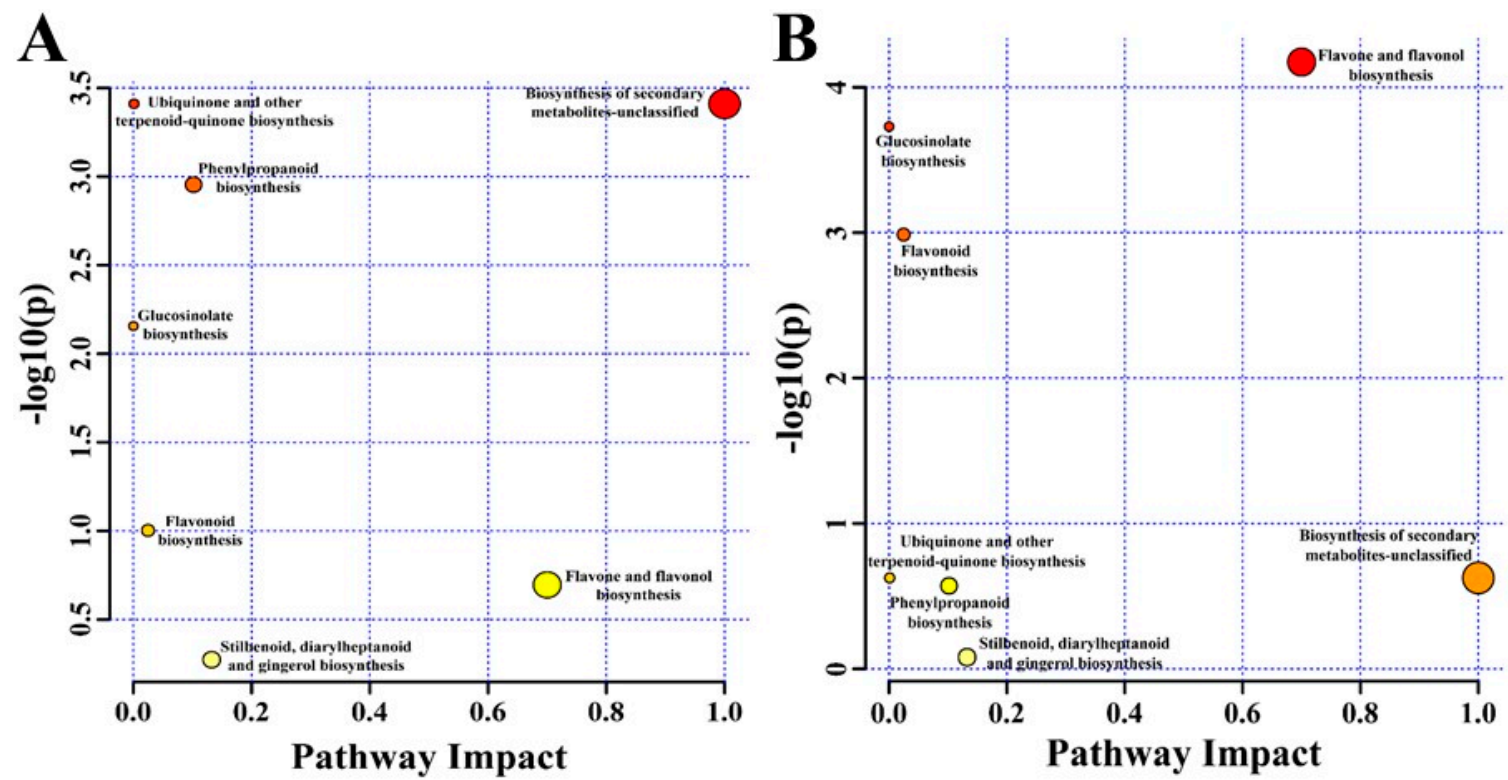

Figure 5. Identified secondary metabolites and their pathway impact in PGK (A) and PK (B) cultivars grown under light and dark conditions. 
The accumulation of metabolites in the PGK and PK cultivars grown under the light and dark conditions were clarified based on hierarchical clustering analysis and the heat map obtained for the 23 metabolites identified in both cultivars (Figure 6). Two major clades were obtained with different patterns owing to the abundance of altered metabolites between the cultivars. The differential pattern of metabolite clustering clearly showed the metabolic changes, similar to the results obtained in groundnut, rice, and Cannabis [40-42]. The significantly higher $(p \leq 0.05)$ individual metabolites in both cultivars are shown in Figure S1.

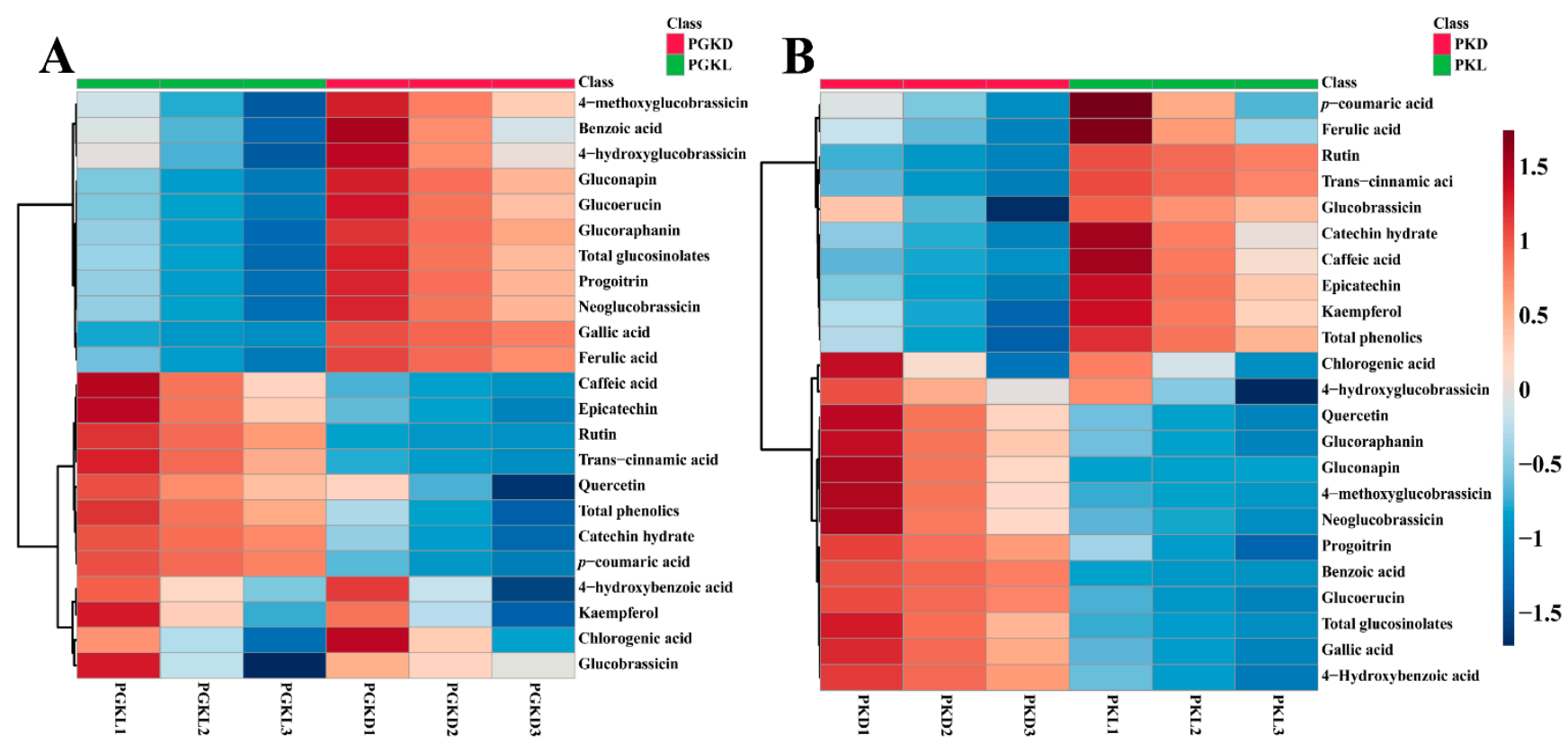

Figure 6. Heatmap (A) representing differences in the relative secondary metabolites concentration in the PGK cultivar grown under light and dark conditions, (B) representing differences in the relative secondary metabolites concentration in the PK cultivar grown under light and dark conditions.

A previous study reported that light irradiation triggers the growth and metabolite production of hairy roots. In the hairy roots of Acmella oppositifolia, Datura stramonium, and Lippia dulcis, the color of the root changed to green because light irradiation resulted in the enhanced accumulation of phytochemical compounds [43]. In addition, the levels of rutin and baicalein significantly increased in the hairy roots of Scutellaria lateriflora and Fagopyrum tataricum grown under light when compared to those of plants grown under dark conditions [44,45]. Similarly, with continuous exposure to light at $60 \mu \mathrm{mol} \mathrm{s}$ $\mathrm{m}^{-2}$, the concentration of anthocyanins, chlorogenic acid, caffeic acid, and cichoric acid increased in the hairy root of Echinacea purpurea compared to that in the dark-grown hairy roots [46]. These results support those obtained in this study that show light enhances the accumulation PCs, whereas the dark enhances the accumulation of glucosinolate compounds. In addition, the PCA result also showed that most of the eigenvector values of PCs showed a positive correlation, whereas those of most of the glucosinolates compounds showed a negative correlation.

\section{Conclusions}

This study might extend our understanding of the molecular mechanisms involved in PCs and glucosinolates biosynthesis and identifies targets for increasing the production of both compounds in the seedlings of kohlrabi and other species. Our findings suggest that the application of light induces increased production of PCs and that glucosinolates production was significantly induced in dark conditions during the development of kohlrabi seedlings. The present information regarding the identity and contents of PCs and glu- 
cosinolates present in PGK and PK for human consumption might be helpful in future databases.

Supplementary Materials: The following are available online at https:/ / www.mdpi.com/article / 10.3390 /agronomy11101939/s1, Figure S1: Individual metabolites that are significantly $(p \leq 0.05)$ higher either in PGK and PK grown under light and dark conditions. Table S1: Metabolic pathways where the identified metabolites are involved in PGKLD and PKLD.

Author Contributions: S.U.P. and J.K. conceived the study; R.S., M.C.K., H.J.Y., B.V.N. and S.I.S. performed the experiments and analyzed the data; R.S. wrote the original draft; R.S., S.U.P. and J.K. performed writing-review and editing. All authors have read and agreed to the published version of the manuscript.

Funding: This work was supported by a grant from the New Breeding Technologies development Program (Project No. PJ014929032021), Rural Development Administration, Republic of Korea.

Institutional Review Board Statement: Not applicable.

Informed Consent Statement: Not applicable.

Data Availability Statement: Data reported are available in the Supplementary Materials.

Conflicts of Interest: The authors declare no conflict of interest.

\section{References}

1. Park, W.T.; Kim, J.K.; Park, S.; Lee, S.-W.; Li, X.; Kim, Y.B.; Uddin, M.R.; Park, N.I.; Kim, S.-J.; Park, S.U. Metabolic profiling of glucosinolates, anthocyanins, carotenoids, and other secondary metabolites in kohlrabi (Brassica oleracea var. gongylodes). J. Agric. Food Chem. 2012, 60, 8111-8116. [CrossRef] [PubMed]

2. Jung, H.A.; Karki, S.; Ehom, N.-Y.; Yoon, M.-H.; Kim, E.J.; Choi, J.S. Anti-diabetic and anti-inflammatory effects of green and red kohlrabi cultivars (Brassica oleracea var. gongylodes). Prev. Nutr. Food Sci. 2014, 19, 281. [CrossRef]

3. Park, C.H.; Yeo, H.J.; Kim, N.S.; Eun, P.Y.; Kim, S.-J.; Arasu, M.V.; Al-Dhabi, N.A.; Park, S.-Y.; Kim, J.K.; Park, S.U. Metabolic profiling of pale green and purple kohlrabi (Brassica oleracea var. gongylodes). Appl. Biol. Chem. 2017, 60, 249-257. [CrossRef]

4. Pott, D.M.; Osorio, S.; Vallarino, J.G. From central to specialized metabolism: An overview of some secondary compounds derived from the primary metabolism for their role in conferring nutritional and organoleptic characteristics to fruit. Front. Plant Sci. 2019, 10, 835. [CrossRef]

5. Chiocchio, I.; Mandrone, M.; Tomasi, P.; Marincich, L.; Poli, F. Plant secondary metabolites: An opportunity for circular economy. Molecules 2021, 26, 495. [CrossRef] [PubMed]

6. Erb, M.; Kliebenstein, D.J. Plant secondary metabolites as defenses, regulators, and primary metabolites: The blurred functional trichotomy. Plant Physiol. 2020, 184, 39-52. [CrossRef] [PubMed]

7. Lattanzio, V. Phenolic Compounds: Introduction. In Natural Products; Ramawat, K., Mérillon, J.M., Eds.; Springer: Berlin/Heidelberg, Germany, 2013; pp. 1543-1580.

8. Le Roy, J.; Huss, B.; Creach, A.; Hawkins, S.; Neutelings, G. Glycosylation is a major regulator of phenylpropanoid availability and biological activity in plants. Front. Plant Sci. 2016, 7, 735. [CrossRef]

9. Cheynier, V. Phenolic compounds: From plants to foods. Phytochem. Rev. 2012, 11, 153-177. [CrossRef]

10. Lee, H.; Oh, I.-N.; Kim, J.; Jung, D.; Cuong, N.P.; Kim, Y.; Lee, J.; Kwon, O.; Park, S.U.; Lim, Y. Phenolic compound profiles and their seasonal variations in new red-phenotype head-forming Chinese cabbages. LWT 2018, 90, 433-439. [CrossRef]

11. Dinkova-Kostova, A.T.; Kostov, R.V. Glucosinolates and isothiocyanates in health and disease. Trends Mol. Med. 2012, 18, 337-347. [CrossRef]

12. Clarke, D.B. Glucosinolates, structures and analysis in food. Anal. Methods 2010, 2, 310-325. [CrossRef]

13. Kim, Y.B.; Li, X.; Kim, S.-J.; Kim, H.H.; Lee, J.; Kim, H.; Park, S.U. MYB transcription factors regulate glucosinolate biosynthesis in different organs of Chinese cabbage (Brassica rapa ssp. pekinensis). Molecules 2013, 18, 8682-8695. [CrossRef]

14. Al-Gendy, A.; El-Gindi, O.; Hafez, A.S.; Ateya, A. Glucosinolates, volatile constituents and biological activities of Erysimum corinthium Boiss. (Brassicaceae). Food Chem. 2010, 118, 519-524. [CrossRef]

15. Bednarek, P.; Piślewska-Bednarek, M.; Svatoš, A.; Schneider, B.; Doubský, J.; Mansurova, M.; Humphry, M.; Consonni, C.; Panstruga, R.; Sanchez-Vallet, A. A glucosinolate metabolism pathway in living plant cells mediates broad-spectrum antifungal defense. Science 2009, 323, 101-106. [CrossRef]

16. Carvalho, S.D.; Folta, K.M. Environmentally modified organisms-expanding genetic potential with light. Crit. Rev. Plant Sci. 2014, 33, 486-508. [CrossRef]

17. Carvalho, S.D.; Folta, K.M. Sequential light programs shape kale (Brassica napus) sprout appearance and alter metabolic and nutrient content. Hortic. Res. 2014, 1, 1-13. [CrossRef] [PubMed]

18. Yeo, H.J.; Baek, S.-A.; Sathasivam, R.; Kim, J.K.; Park, S.U. Metabolomic analysis reveals the interaction of primary and secondary metabolism in white, pale green, and green pak choi (Brassica rapa subsp. chinensis). Appl. Biol. Chem. 2021, 64, 1-16. [CrossRef] 
19. Park, W.T.; Kim, Y.B.; Seo, J.M.; Kim, S.-J.; Chung, E.; Lee, J.-H.; Park, S.U. Accumulation of anthocyanin and associated gene expression in radish sprouts exposed to light and methyl jasmonate. J. Agric. Food Chem. 2013, 61, 4127-4132. [CrossRef] [PubMed]

20. Li, X.; Thwe, A.A.; Park, N.I.; Suzuki, T.; Kim, S.J.; Park, S.U. Accumulation of phenylpropanoids and correlated gene expression during the development of tartary buckwheat sprouts. J. Agric. Food Chem. 2012, 60, 5629-5635. [CrossRef]

21. Kim, S.-J.; Zaidul, I.; Suzuki, T.; Mukasa, Y.; Hashimoto, N.; Takigawa, S.; Noda, T.; Matsuura-Endo, C.; Yamauchi, H. Comparison of phenolic compositions between common and tartary buckwheat (Fagopyrum) sprouts. Food Chem. 2008, 110, 814-820. [CrossRef]

22. Bellini, E.; Martelli, M. Anthocyanin synthesis in radish seedlings: Effects of continuous far red irradiation and phytochrome transformations. Z. Pflanzenphysiol. 1973, 70, 12-21. [CrossRef]

23. Pizarro, L.; Stange, C. Light-dependent regulation of carotenoid biosynthesis in plants. Cienc. Investig. Agrar. 2009, 36, 143-162. [CrossRef]

24. Sathasivam, R.; Radhakrishnan, R.; Kim, J.K.; Park, S.U. An update on biosynthesis and regulation of carotenoids in plants. S. Afr. J. Bot. 2021, 140, 290-302. [CrossRef]

25. Tuan, P.A.; Thwe, A.A.; Kim, J.K.; Kim, Y.B.; Lee, S.; Park, S.U. Molecular characterisation and the light-dark regulation of carotenoid biosynthesis in sprouts of tartary buckwheat (Fagopyrum tataricum Gaertn.). Food Chem. 2013, 141, $3803-3812$. [CrossRef] [PubMed]

26. Bakhshi, D.; Arakawa, O. Induction of phenolic compounds biosynthesis with light irradiation in the flesh of red and yellow apples. J. Appl. Hortic. 2006, 8, 101-104. [CrossRef]

27. Feys, B.J.; Benedetti, C.E.; Penfold, C.N.; Turner, J.G. Arabidopsis mutants selected for resistance to the phytotoxin coronatine are male sterile, insensitive to methyl jasmonate, and resistant to a bacterial pathogen. Plant Cell 1994, 6, 751-759. [CrossRef] [PubMed]

28. Saniewski, M.; Miyamoto, K.; Ueda, J. Methyl jasmonate induces gums and stimulates anthocyanin accumulation in peach shoots. J. Plant Growth Regul. 1998, 17, 121-124. [CrossRef]

29. Franceschi, V.R.; Grimes, H.D. Induction of soybean vegetative storage proteins and anthocyanins by low-level atmospheric methyl jasmonate. Proc. Natl. Acad. Sci. USA 1991, 88, 6745-6749. [CrossRef]

30. Saniewski, M.; Miszczak, A.; Kawa-Miszczak, L.; Wegrzynowicz-Lesiak, E.; Miyamoto, K.; Ueda, J. Effects of methyl jasmonate on anthocyanin accumulation, ethylene production, and $\mathrm{CO}_{2}$ evolution in uncooled and cooled tulip bulbs. J. Plant Growth Regul. 1998, 17, 33-37. [CrossRef]

31. Francisco, M.; Velasco, P.; Moreno, D.A.; García-Viguera, C.; Cartea, M.E. Cooking methods of Brassica rapa affect the preservation of glucosinolates, phenolics and vitamin C. Food Res. Int. 2010, 43, 1455-1463. [CrossRef]

32. Harbaum, B.; Hubbermann, E.M.; Wolff, C.; Herges, R.; Zhu, Z.; Schwarz, K. Identification of flavonoids and hydroxycinnamic acids in pak choi varieties (Brassica campestris L. ssp. chinensis var. communis) by HPLC-ESI-MS n and NMR and Their Quantification by HPLC-DAD. J. Agric. Food Chem. 2007, 55, 8251-8260. [CrossRef]

33. Fernandes, F.; Valentão, P.; Sousa, C.; Pereira, J.A.; Seabra, R.M.; Andrade, P.B. Chemical and antioxidative assessment of dietary turnip (Brassica rapa var. rapa L.). Food Chem. 2007, 105, 1003-1010. [CrossRef]

34. Ferreres, F.; Sousa, C.; Vrchovská, V.; Valentão, P.; Pereira, J.A.; Seabra, R.M.; Andrade, P.B. Chemical composition and antioxidant activity of tronchuda cabbage internal leaves. Eur. Food Res. Technol. 2006, 222, 88-98. [CrossRef]

35. Kim, S.-J.; Zaidul, I.; Maeda, T.; Suzuki, T.; Hashimoto, N.; Takigawa, S.; Noda, T.; Matsuura-Endo, C.; Yamauchi, H. A time-course study of flavonoids in the sprouts of tartary (Fagopyrum tataricum Gaertn.) buckwheats. Sci. Hortic. 2007, 115, 13-18. [CrossRef]

36. Watanabe, M. An anthocyanin compound in buckwheat sprouts and its contribution to antioxidant capacity. Biosci. Biotechnol. Biochem. 2007, 71, 579-582. [CrossRef] [PubMed]

37. Jeon, J.; Kim, J.K.; Kim, H.; Kim, Y.J.; Park, Y.J.; Kim, S.J.; Kim, C.; Park, S.U. Transcriptome analysis and metabolic profiling of green and red kale (Brassica oleracea var. acephala) seedlings. Food Chem. 2018, 241, 7-13. [CrossRef]

38. Park, C.H.; Bong, S.J.; Lim, C.J.; Kim, J.K.; Park, S.U. Transcriptome analysis and metabolic profiling of green and red mizuna (Brassica rapa L. var. japonica). Foods 2020, 9, 1079. [CrossRef]

39. Park, C.H.; Kwon, S.-J.; Kim, N.S.; Baek, S.-A.; Yeo, H.J.; Park, Y.E.; Chung, Y.S.; Kim, J.K.; Park, S.U. Metabolic analysis of carotenoids and phenolic compounds found in green and purple kenaf. Nat. Prod. Commun. 2020, 15, 1934578X20971138.

40. Rashid, A.; Ali, V.; Khajuria, M.; Faiz, S.; Gairola, S.; Vyas, D. GC-MS based metabolomic approach to understand nutraceutical potential of Cannabis seeds from two different environments. Food Chem. 2021, 339, 128076. [CrossRef]

41. Raval, S.S.; Mahatma, M.K.; Chakraborty, K.; Bishi, S.K.; Singh, A.L.; Rathod, K.J.; Jadav, J.K.; Sanghani, J.M.; Mandavia, M.K.; Gajera, H.P. Metabolomics of groundnut (Arachis hypogaea L.) genotypes under varying temperature regimes. Plant Growth Regul. 2018, 84, 493-505. [CrossRef]

42. Yan, S.; Huang, W.; Gao, J.; Fu, H.; Liu, J. Comparative metabolomic analysis of seed metabolites associated with seed storability in rice (Oryza sativa L.) during natural aging. Plant Physiol. Biochem. 2018, 127, 590-598. [CrossRef]

43. Jacob, A.; Malpathak, N. Green hairy root cultures of Solanum khasianum Clarke-A new route to in vitro solasodine production. Curr. Sci. 2004, 87, 1442-1447.

44. Thwe, A.A.; Kim, Y.; Li, X.; Kim, Y.B.; Park, N.-I.; Kim, H.H.; Kim, S.-J.; Park, S.U. Accumulation of phenylpropanoids and correlated gene expression in hairy roots of tartary buckwheat under light and dark conditions. Appl. Biochem. Biotechnol. 2014, 174, 2537-2547. [CrossRef] [PubMed] 
45. Marsh, Z.; Yang, T.; Nopo-Olazabal, L.; Wu, S.; Ingle, T.; Joshee, N.; Medina-Bolivar, F. Effect of light, methyl jasmonate and cyclodextrin on production of phenolic compounds in hairy root cultures of Scutellaria lateriflora. Phytochemistry 2014, 107, 50-60. [CrossRef] [PubMed]

46. Abbasi, B.H.; Tian, C.-L.; Murch, S.J.; Saxena, P.K.; Liu, C.-Z. Light-enhanced caffeic acid derivatives biosynthesis in hairy root cultures of Echinacea purpurea. Plant Cell Rep. 2007, 26, 1367-1372. [CrossRef] 